M. Elmquist ${ }^{(1)}$, A. Gawer ${ }^{(2)}$, P. Le Masson*(3)

(1) Department of Technology Management and Economics, Chalmers University of Technology, Sweden

(2) Surrey Business School, Centre for the Digital Economy, University of Surrey, Guildford, GU2 7XH, United Kingdom

(3) Center for Management Science-i3 UMR CNRS 9217, Mines ParisTech, PSL Research University, France

* This is a co-authored editorial; authors appear in alphabetical order. Corresponding author: pascal.le masson@mines-paristech.fr; mail address: MINES ParisTech - PSL Research University, 60 boulevard Saint Michel, 75006 Paris, France 


\section{Innovation Theory and the (Re-)foundation of Management: \\ Facing the Unknown}

\section{Setting the stage for this special issue}

Within the management research community, the last few years have revealed a growing desire to focus explicitly on new discoveries and to challenge the very foundations of our discipline. This special issue addresses how innovation-management theories might enrich management science, helping to discover new phenomena and formulate research hypotheses with relevance for the entire discipline.

Contemporary managers face many challenges when shaping new industrial ecosystems, engaging with disruptive technologies, inventing new business models, or even re-inventing their own organizations. An interesting recurring theme in all these contexts is that they involve not just uncertainty, but facing the unknown. While uncertainty refers to events that are known, and whose probability of occurrence can be estimated (as inherited from statistical decision theory), the unknown denotes events that can be expressed conceptually, but can hardly be imagined, and therefore cannot be described. For example, tomorrow's weather is uncertain, but forms of extraterrestrial life are unknown. While uncertainty can be reduced (e.g. by statistical sampling), the unknown must be explored through an effort of imagination.

In innovation management, the way innovators relate to the future is closer to exploring the unknown. They don't regard the future as "uncertain," but as a matter that has to be shaped, transformed, named, and generally invented in a proactive way. This perspective could also be useful to general management.

Some innovation management concepts have already enriched mainstream management literature. "Organizational ambidexterity" (Duncan 1976; Tushman and O'Reilly III 1996; Tushman et al. 2010; Gibson and Birkinshaw 2004), which was initially proposed as a way of organizing for innovation, has more recently been acknowledged as a fundamental notion in organization studies (Birkinshaw and Gupta 2013). The concept of "absorptive capacity" has enjoyed a similar crossover. But despite these individual examples, innovation management has largely remained a "specialization," as illustrated by journal rankings in many countries, preventing it from taking root in management science. The purpose of this special Issue is to bring insights from innovation management to the very heart our discipline.

We now summarize the six papers included, before discussing how they contribute to (re)visiting and (re-)founding management science with innovation theory.

Six contributions linking innovation management and management foundations

In "Understanding the invention phase of management innovation: a design theory perspective," Albert David examines the invention process of a single famous management innovation: Drucker's “Management by Objectives" (MBO) concept.

In "A century old and still visionary: Fayol's innovative theory of management," Armand Hatchuel and Blanche Segrestin revisit Fayol's legacy and argue that, contrary to previous analysis, Fayol positioned innovation at the very core of management science.

In "Contracting for the unknown and the logic of innovation," Anna Grandori and Marco Furlotti identify specific types of contracts for managing innovation, which they term "constitutional contracts." 
In "The design logic of new business models: unveiling cognitive foundations of managerial reasoning," Dirk Schneckenberg and Vivek Velamuri uncover the cognitive processes used in creating innovative business models.

In "Experimenting in the unknown: Lessons from the Manhattan Project," Sylvain Lenfle and Thomas Gillier show that Thomke's model of experimentation was actually built for experimentation in uncertainty, and extend it to the unknown.

Finally, in "Designing decisions in the unknown: towards a generative decision model for management science," Pascal Le Masson, Armand Hatchuel, Mario Le Glatin, and Benoit Weil address the issue of designing decisions in the unknown.

(Re-) visiting and (re-)founding management science with innovation management It is a privilege to be able to include, in just one issue, papers addressing the work of groundbreaking founders of management science such as Fayol (Hatchuel and Segrestin 2018), Wald (Le Masson et al. 2018), Drucker (David 2018), and Simon (Grandori and Furlotti 2018). These new papers will encourage our readers to reengage with the legacy that these great authors left to management science. The papers also provide a panorama of the management science discipline, from its historical roots (Fayol) to the most recent trends (business-model innovation), while revisiting key inflection points (e.g., Drucker). Last but not least, the papers adopt a trans-disciplinary perspective: even as they work towards the (re)foundation of management science, they articulate its position in relation to other disciplines such as economics and sociology (Hatchuel and Segrestin 2018); re-examine its roots in statistics (Le Masson et al. 2018; Lenfle and Gillier 2018); and make use of cognitive science approaches (Schneckenberg and Velamuri 2018; Le Masson et al. 2018), legal concepts (Grandori and Furlotti 2018), and design theory (David 2018; Grandori and Furlotti 2018; Le Masson et al. 2018).

Beyond this rich panorama, there are three ways in which the six papers, taken together, contribute to the (re-)foundation of management science using specific concepts from innovation management.

1) Revisiting the classics

First, the papers exhort us to revisit some classic notions of the management discipline. It is inspiring to see how each paper, taking the perspective of innovation management, uncovers new limitations of established theories and pushes research to go beyond the "common sense" of management. David discusses "Management by Objectives," often taken to be a self-evident notion. Hatchuel and Segrestin revisit Fayol's administrative theory, which is usually seen as the application of scientific rationality to administration. Grandori and Furlotti revisit a commonly admitted assumption-namely, that contracting in the unknown necessarily leads to an "incomplete contract." Schneckenberg and Velamuri explain that business models can no longer be considered a reference frame for how to meaningfully interpret information in contexts that include high levels of both complexity and novelty. Lenfle and Gillier revisit the notion of experimentation, which is usually considered a good way to reduce uncertainty. Finally, Le Masson et al. show that decision-making is not the only way to behave rationally. In so doing, they re-examine not only rational decision-making, but also its inherent dark side: the assumption that creativity is necessarily irrational.

2) New methods inspired by innovation-management research

A second contribution is that the papers propose a set of new methods, stemming from innovation management, to extend the classics. David and Le Masson et al. apply design 
theory to management classics: the invention of managerial notions (David) and the decision (Le Masson et al.). Meanwhile, the papers by David and Hatchuel and Segrestin rely on historical method and a genealogical approach to understand the evolution and dynamics of meanings.

3) New notions to extend the classics and (re-)found management science

The third contribution may be the most important: by revisiting the classics, the papers don't just raise criticisms - they also propose new notions to extend classic ones.

For instance, David analyzes the unknown in management techniques-the paper shows how the design perspective uncovers the internal coherence of a managerial technique, beyond its multiple facets such as process, practice, instrument, organization principle, mindset, and performance logic. The author considers management as a design process and management innovations as the managerial artifacts that result from such design effort.

After discussing the limitations of contracts, which imply known outcomes and clear problems to be solved, Grandori and Furlotti propose a new notion. "Constitutional contracting" is adapted for facing "the unknown," and situations where "means are in search of uses." This new contractual type is procedural rather than substantive, constitutional rather than operational, and democratic rather than hierarchical.

Gillier and Lenfle propose new principles to extend the logic of experimentation in the unknown, based on the capacities to identify the unknown (not just the uncertain), to design new descriptors (and the formal models and theories attached to them), and to design the instruments to characterize these new descriptors.

Le Masson et al. propose a formal model to systematically map the design paths leading to the design of new decision options. The authors show that contemporary design theory can help us plot a systematic, rational path to design decisions in the unknown.

Finally, Hatchuel and Segrestin, revisiting Fayol's legacy, reveal that, for Fayol, management science is inseparable from innovation. Following Fayol, who put the logic of innovation at the heart of managerial action, management is necessarily a theory of creative/political rationality where collective action is structured by coping with the unknown. This suggests that management should be the science of "creative, scientific, economics and social advancements."

\section{Management science as a science of the design of collective action}

Of course, these six papers are but a small sample of all the efforts to link innovation theory and management science. Nonetheless, they invite us to develop this collective endeavor more systematically. They also remind us that modern management was created by innovators such as Taylor, Fayol, and Parker Follett (O'Connor 2000)-famous founders who did not just conceptualize and characterize new forms of collective actions, but even invented them. These works remind us that innovation was historically at the heart of management science-and that without innovation, management science would be locked into a spiral of imitation and reproduction.

Moreover, the work in this issue illustrates that innovation management today pushes us to revise and challenge the basic notions of management science. Previous discussions in management science have elaborated theory by building polarities, often corresponding to "theory" vs. "practice" or "optimal rationality" vs. collective heuristics and biases. But managing in the unknown obliges us to go beyond such polarities. We need a new rationality: 
the design of new forms of collective action. These six papers help unfold this new paradigm of management science.

If management is about designing collective action, management science can be considered the science of inventing new organizational logics, new rationality, and new values. It is management science that discovers these things; conceptualizes them; perhaps even proposes them and helps experiment with them. This new paradigm is coherent with the essence of management science (see Hatchuel 2005), which is neither a fixed repertoire of forms (and hence different from an "applied sociology") nor the direct consequence of rational optimization (and hence different from an "applied economics"). This new paradigm of management science also has a promising future, because it constitutes a "post-decisional" paradigm-one adapted to contemporary unknowns and the invention of new societies, new industries, new skills, new knowledge, and new dreams of the future.

We hope you will enjoy these six papers as much as we do, and that your insights and inspiration will repay the efforts of all the authors, reviewers, and editors who have worked so hard to produce this special issue. We owe them all a great debt of gratitude. 


\section{References}

Birkinshaw J, Gupta K (2013) Clarifying the Distinctive Contribution of Ambidexterity to the Field of Organization Studies. The Academy of Management Perspectives 27 (4):287298.

David A (2018) Understanding the invention phase of management innovation: a design theory perspective. European Management Review To be published.

Duncan RB (1976) The ambidextrous organization: designing dual structures for innovation. In: Kilmann LR, Pondy LR, Slevin DP (eds) The management of organizational Design: Strategy Implementation, vol 1. North Holland, New York, pp 167-188

Gibson CB, Birkinshaw J (2004) The Antecedents, Consequences, and Mediating Role of Organizational Ambidexterity. Academy of Management Journal 47 (2):209-226.

Grandori A, Furlotti M (2018) Contracting for the unknown and the logic of innovation. European Management Review To be published.

Hatchuel A (2005) Towards an epistemology of collective action. Management research as a responsive and actionable discipline. European Management Review 2:36-44.

Hatchuel A, Segrestin B (2018) A century old and still visionary: Fayol's innovative theory of management. European Management Review To be published.

Le Masson P, Hatchuel A, Le Glatin M, Weil B (2018) Designing decisions in the unknown: towards a generative decision model for management science. European Management Review To be published.

Lenfle S, Gillier T (2018) Experimenting in the Unknown: Lessons from The Manhattan Project. European Management Review To be published.

O'Connor ES (2000) Integrating Follett: history, philosophy and management. Journal of Management History (Archive) 6 (4):167-190.

Schneckenberg D, Velamuri V (2018) The design logic of new business models: unveiling cognitive foundations of managerial reasoning. European Management Review To be published.

Tushman M, Smith WK, Chapman Wood R, Westerman G, O'Reilly C (2010) Organizational designs and innovation streams. Industrial and Corporate Change 19 (5):1331-1366.

Tushman ML, O'Reilly III CA (1996) Ambidextrous Organizations: Managing Evolutionary and Revolutionary Change. California Management Review 38 (4):8-30. 